\title{
Biosynthesis of silver nanocomposite with Tarragon leaf extract and assessment of antibacterial activity
}

\author{
Sariyeh Omidi ${ }^{1} \cdot$ Sajjad Sedaghat ${ }^{2} \cdot$ Kambiz Tahvildari $^{1} \cdot$ Pirouz Derakhshi $^{1} \cdot$ Fereshte Motiee $^{1}$
}

Received: 27 January 2018 / Accepted: 14 May 2018 / Published online: 1 June 2018

(c) The Author(s) 2018

\begin{abstract}
The aqueous extract of Tarragon, as a reducing agent, was used to synthesize silver-montmorillonite (MMT) nanocomposite (Ag-MMT-NPs) in the batch method. The leaf extract and metal solution concentrations were optimized to improve $\mathrm{Ag}-\mathrm{MMT}-\mathrm{NPs}$ synthesis in $48 \mathrm{~h}$. For characterizing the nanocomposite, powder X-ray diffraction (XRD), Fourier transform infrared spectroscopy (FTIR), Transmission electron microscopy (TEM), and UV-Vis spectroscopy were performed. The peak was observed at $437 \mathrm{~nm}$ on the UV-Vis spectrum, showing the surface plasmon resonance of Ag-MMT-NPs. Using XRD analysis, the crystalline nature and purity of Ag-MMT-NPs were confirmed. FTIR was used to evaluate specific functional groups, causing a reduction in silver nitrate during Ag-MMT-NPs formation. According to TEM, the average particle size was $25.12 \mathrm{~nm}$ in AgNPs. The nanocomposite showed antibacterial properties against Gram-negative and Gram-positive bacteria (Escherichia coli and Staphylococcus aureus).
\end{abstract}

Sajjad Sedaghat

Sajjadsedaghat@yahoo.com; sajjad_sedaghat@yahoo.com

Sariyeh Omidi

sariyeh@yahoo.com

Kambiz Tahvildari

K_tahvildari@iau-tnb.ac.ir

Pirouz Derakhshi

Pirouz1@dr.com

Fereshte Motiee

F_motiee@iau-tnb.ac.ir

1 Department of Chemistry, College of Science, North Tehran Branch, Islamic Azad University, Tehran 1913674711, Iran

2 Department of Chemistry, College of Science, Shahr-e-Qods Branch, Islamic Azad University, Shahr-e-Qods,

Tehran 3754113115, Iran 


\section{Graphical Abstract}
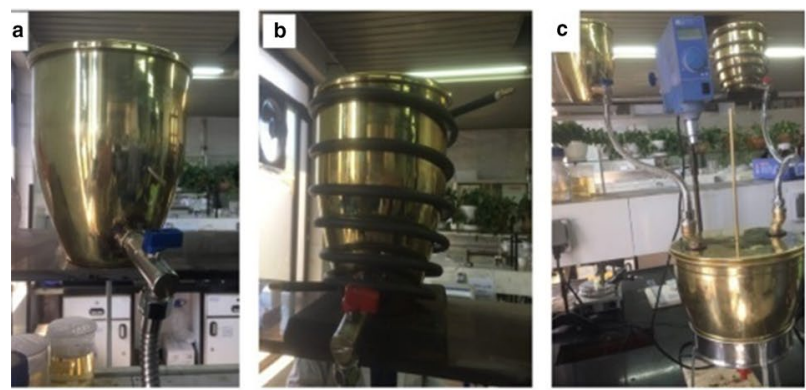

plant extract $+\mathrm{AgNO}_{3} \rightleftharpoons \mathrm{AgNPs}$
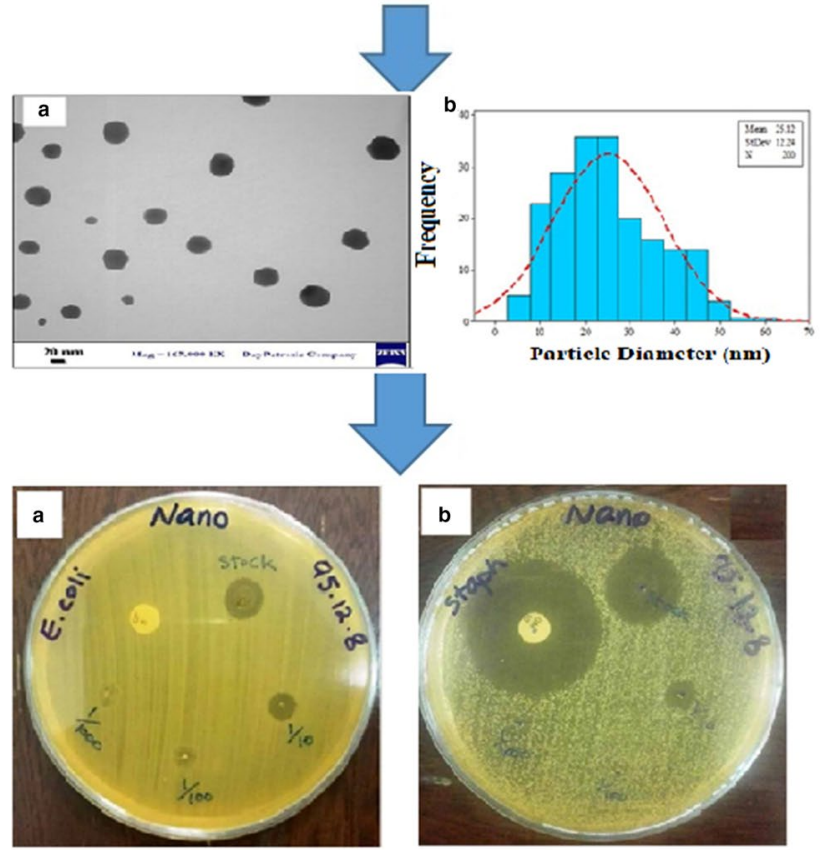

Keywords Biosynthesis $\cdot$ Silver nanoparticles $\cdot$ Montmorillonite $\cdot$ Tarragon $\cdot$ SEM

\section{Abbreviations}

XRD

X-ray diffraction

FTIR Fourier transform infrared spectroscopy

TEM Transmission electron microscopy

SPR Surface plasmon resonance

E. coli Escherichia coli

S. aureus Staphylococcus aureus

AgNPs Silver nanoparticles

UV-Vis Ultraviolet-visible

FWHM Full width half maxima

MBC Minimum bactericidal concentration

MIC Minimum inhibitory concentration

\section{Introduction}

Nanotechnology research and development has been an area of rapid growth worldwide [1]. Silver nanoparticles (AgNPs) are one of the most extensively used varieties of NPs [2], with a large number of applications. AgNPs are used as coating in solar energy absorption. Moreover, they are used as optical receptors, biological labels, and intercalating materials for electrical batteries [3]. So far, metals, such as Ag, $\mathrm{Au}, \mathrm{Pd}$, and $\mathrm{CdS}$, have been used for synthesizing metal NPs, Thus, the synthesis of Ag-NPs onto MMT supports with swelling and ion exchange properties is a good way to control the particle size $[4,5]$. AgNPs exhibit important chemical, physical, and biological characteristics among metal NPs [6] and have potential applications in antimicrobial, anticancer, cosmetic, paint, food packing, and textile 
industries [7]. Many techniques have been investigated for synthesizing AgNPs, including physical, chemical, and, most recently, biological methods [8]. The chemical synthesis of NPs is rapid, but requires the use of toxic, hazardous chemicals such as sodium borohydride, hydrazine, hydroxylamine, and ethanol [9]. Additionally, with chemical synthesis, it is difficult to control the stability, growth, and aggregation of particles, and capping agents are required for stabilization of NP size [2]. Recently, great attention has been directed towards plant extracts for NP [10], and Ag/nanocomposites synthesis [11]. Use of biosynthetic green metal NPs is gaining increasing approval owing to its simplicity, non-toxicity, and amenability to large-scale production [12].

AgNP synthesis has been evaluated in different extracts, including Medicago sativa [13], Ulva flexuosa [14], Achillea biebersteinii [15], Moringa oleifera [16], Calendula officinalis [17], Peganum harmala [18], Green Tea [19], Pistacia atlantica [20], olive [21], Aloe vera [22], and Coriandrum Sativum [23]. We developed a simple, rapid, and green method to synthesize AgNPs, using MMT and Tarragon leaf extract as both a reducing and capping agent under normal atmospheric conditions in the batch method in this study. This method is easily adopted for large-scale synthesis of NPs, without requiring any extra compounds or physical processes [24].

Simple collection and widespread availability of Tarragon, coupled with its remarkable biological activity, have led to its use as a medicine in many countries [25]. Tarragon has been recently shown to have wide-ranging antimicrobial activities [26]. Based on some researchers, Tarragon has been shown to have antimicrobial activities against two bacteria Staphylococcus aureus and Escherichia coli [27]. The size of synthesized AgNPs with Tarragon extract is smaller as compared to the many earlier green synthesis reports [1,2]. Reaction of Tarragon extract with aqueous metal solution $\left(\mathrm{AgNO}_{3}\right)$ yields only spherical nanoparticles. The leaf extract and metal solution $\left(\mathrm{AgNO}_{3}\right)$ concentrations were optimized to improve AgNP synthesis. AgNPs were characterized by methods, including powder X-ray diffraction, UV-Vis spectroscopy, Transmission electron microscopy, and Fourier transform infrared spectroscopy. The disk diffusion method was applied to evaluate the antibacterial potential of AgNPs.

\section{Materials and methods}

\section{Preparing of silver nanoparticles with Tarragon extract}

Green A. dracunculus leaves were collected from north east of Iran in May 2017. After washing the Tarragon leaves, they were dried under direct light for 3 days at a temperature of $38{ }^{\circ} \mathrm{C} . \mathrm{AgNO}_{3}(99.80 \%)$ was provided by Merck Co. Montmorillonite powder (MMT), used as the solid support, was purchased from Fluka Chemical Co. $0.01 \mathrm{~g}$ of MMT powder was dispersed with vigorous stirring in certain amount of double-distilled water for $1 \mathrm{~h}$. MMT suspension was added to $100 \mathrm{~mL}$ of $0.01(\mathrm{~mol} / \mathrm{L}) \mathrm{AgNO}_{3}$ solutions for the synthesis of Ag/MMT nano composite. The mixture was then added to $20 \mathrm{~mL}$ of $A$. dracunculus water extract at room temperature while sonicating and then vigorously stirred for $48 \mathrm{~h}$. The color changed from yellow to dark brown at room temperature, and AgNPs were gradually obtained during the reaction.

\section{Purification of silver nanoparticles}

To remove silver colloid residues, the solution was first washed with double-distilled water via centrifugation for $15 \mathrm{~min}$ at $4000 \mathrm{rpm}$, and then, washed three times with deionized water. After incubation at $65^{\circ} \mathrm{C}$ for $2 \mathrm{~h}$, the dried powder of Ag-MMT-NPs was collected for further characterization [28]. In other previous similar investigations, the maximum volume used for synthesis of AgNPs has been $50 \mathrm{~mL}$ [18], but in our work the volume was increased to $2000 \mathrm{cc}$ which resulted in synthesizing $2 \mathrm{~g}$ of silver nanoparticles. due to this information, we can claim that this method could be easily adopted for large-scale synthesis of NPs.

\section{UV-Vis spectroscopy}

Considering the UV-Vis spectrum of the reaction medium, AgNP formation was monitored at a wavelength range of 300-800 nm. A UV-Vis spectrophotometer (BioTek) was used to record the spectra. The samples were appropriately diluted with water before each measurement.

\section{Fourier transform infrared (FTIR) spectroscopy}

For determining the functional groups in the synthesis of AgNPs, spectroscopy analyses were performed to describe the functional groups [29], bound distinctively to the surface of AgNPs. Samples were prepared by vacuum-drying the Tarragon extract before and after synthesis of AgNPs. After mixing the dried samples with potassium bromide, they were pressed into a sheer slice. The samples were examined using an FTIR spectrometer (PerkinElmer, USA).

\section{X-ray diffraction (XRD)}

The crystal structure of AgNPs was determined and confirmed via XRD analysis. After placing the air-dried NPs on an XRD grid, they were assessed in terms of AgNP formation, using an $\mathrm{X}$-ray diffractometer $(\mathrm{Cu} \mathrm{K} \alpha$ radiation, $\theta-2 \theta$ configuration; PANalytical) with an X'Pert Pro generator 
(30 mA; $40 \mathrm{kV}$ ). For measuring the crystallite domain size, the XRD peak width was determined under the assumption that non-uniform strains are absent.

\section{Transmission electron microscopy (TEM)}

Morphological analysis of Ag-MMT-NPs was carried out on a Zeiss EM 10C/CR TEM microscope (Zeiss, Germany) at $100 \mathrm{kV}$. The suspension was drop-casted on a carbon-coated copper grid and left to dry overnight at $25^{\circ} \mathrm{C}$.

\section{Antibacterial activity}

For determining the antibacterial activity of Ag-MMT-NPs, the agar disk diffusion method was applied, as previously reported [30]. Briefly, AgNPs at 5, 0.5, and $0.05 \mu \mathrm{g} / \mathrm{mL}$ were used to prevent $E$. coli (ATCC 25922) and $S$. aureus (ATCC 25923) growth. Bacterial cultures at a concentration of $1.5 \times 10^{8} \mathrm{CFU} / \mathrm{mL}$ were inoculated with different concentrations of AgNPs [31]. After incubating the culture plates at $37{ }^{\circ} \mathrm{C}$ for $24 \mathrm{~h}$, the bacterial growth inhibition zone was measured in millimeters [32]. For each bacterial strain, three independent experiments were performed.

\section{Results and discussion}

To investigate whether an aqueous extract of Tarragon can be used in the green synthesis of AgNPs, we combined the extract with 1, 2 and $3 \mathrm{mM}$ of $\mathrm{AgNO}_{3}$ for $24 \mathrm{~h}$. The slow change of color in the solution (from yellow to dark brown) was indicative of AgNP formation. The dark brown color might be related to the surface plasmon resonance (SPR) effect and $\mathrm{AgNO}_{3}$ reduction [33].

\section{UV-Vis spectroscopy}

UV-Vis spectroscopy is an efficient technique for NP analysis, particularly for determining the stability of metal NPs in aqueous solutions. Different concentration of $\mathrm{AgNO}_{3}$ $(1,2$ and $3 \mathrm{mM})$ was reacted with the aqueous extract, and the spectra were recorded at a range of 350-850 $\mathrm{nm}$ [34]; then, the wavelength of maximum absorption was identified. Biosynthesis of AgNPs by the Tarragon extract was confirmed based on changes in color after the addition of $\mathrm{AgNO}_{3}$ (Fig. 1).

Different concentrations of $\mathrm{AgNO}_{3}$ were used for optimization. The analysis showed a sharp plasmon resonance of $3 \mathrm{mM} \mathrm{AgNO}$ at nearly $437 \mathrm{~nm}$ (Fig. 2), consistent with previous reports of peaks in the absorption spectrum of 400-500 nm due to SPR in AgNPs [35, 36]. Without any physical or chemical capping agents, the NPs were dispersed. The Tarragon synthesized AgNPs were quite stable in the solution.

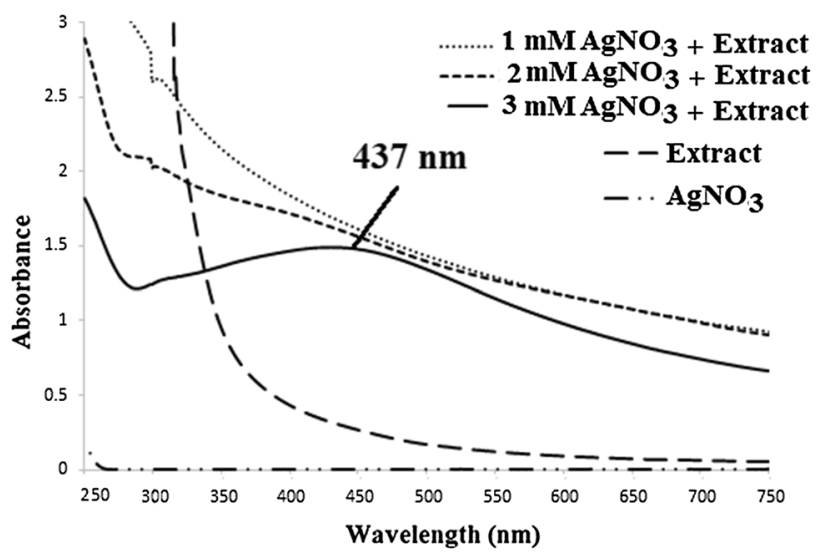

Fig. 2 UV-Vis spectra of synthesized silver nanoparticles using Tarragon extract and $\mathrm{AgNO}_{3}$
Fig. 1 a Extract of Tarragon, b aqueous solutions of silver nitrate $\left(\mathrm{AgNO}_{3}\right)$ and extract of Tarragon (Artemisia dracunculus), c Ag-MMT-NPs after $24 \mathrm{~h}$ of incubation
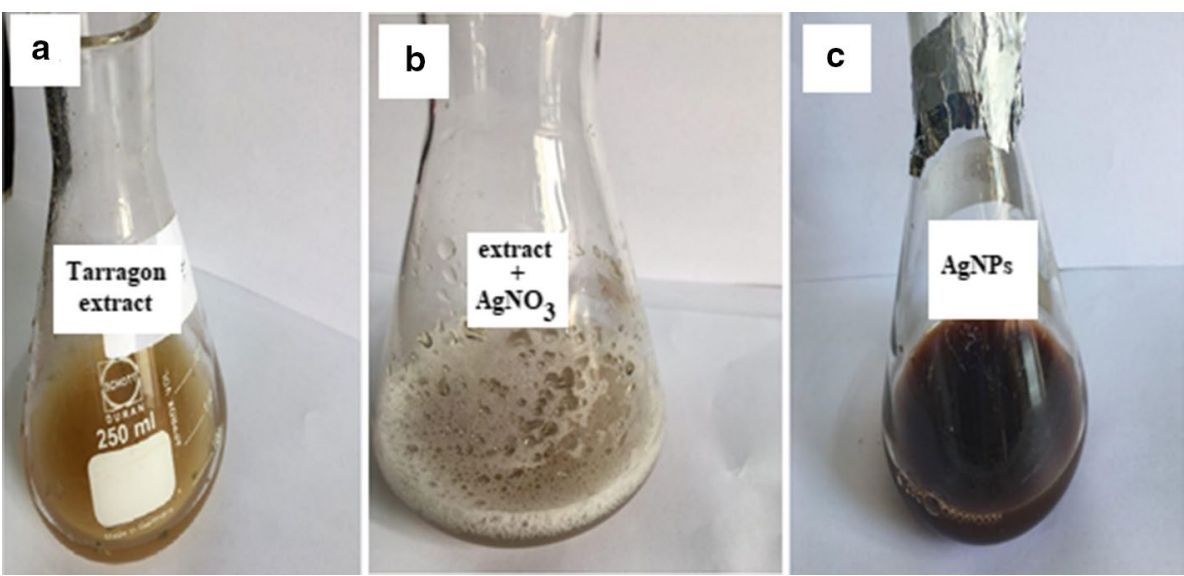


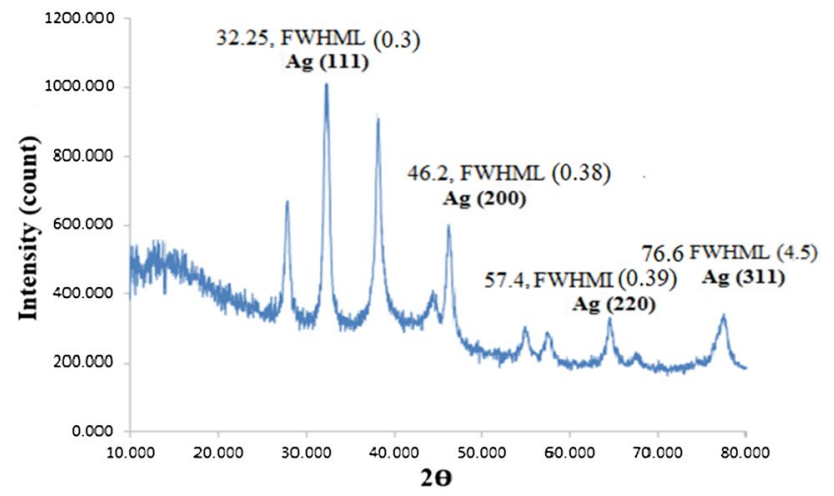

Fig. 3 XRD pattern of Ag-MMT-NPs, indicating crystal structure

\section{XRD analysis}

Using the XRD pattern of synthesized Ag-MMT-NPs, the peaks were attributed to the crystalline planes of Ag-MMT-NPs nanocomposite (Fig. 3). The peaks were very sharp, indicating the crystalline nature of synthesized Ag-MMT-NPs [18].

The diffraction profile had intense peaks at $2 \theta$ of $38.14^{\circ}, 46.2^{\circ}, 64.51^{\circ}$, and $76.6^{\circ}$, corresponding to the (111), (200), (220), and (311) planes, respectively. The mean particles size of AgNPs was evaluated using the Debye-Scherer Eq. (1):

$d=\frac{K \lambda}{\beta \cos \theta}$,

where $\lambda$ denotes the $\mathrm{X}$-ray wavelength (1.540560 $\AA$ ), $\beta$ represents the width of XRD peak, $\theta$ shows the Bragg angle, $d$ refers to the size of particle, and $K$ describes the Scherer constant (0.9) [7]. The average size of AgNPs was almost $28 \mathrm{~nm}$.

\section{FTIR analysis}

In FTIR spectrum, the biomolecules resulting in $\mathrm{Ag}^{0}$ reduction and stabilization can be shown (Fig. 4).

FTIR spectroscopy was carried out to determine the potential biomolecules responsible for the reduction and capping of the AgNPs synthesized. The FTIR spectra of plant extract shows absorption bands characteristics of functional groups such as alcohol, phenol, amine and carbonyl group. In FTIR absorption bands at 3396.66, 1625.75 , and $1427.55 / \mathrm{cm}$ (Fig. 4a). The vibrational bands corresponded to bonds, such as alcohols $(-\mathrm{O}-\mathrm{H})$, alkenes

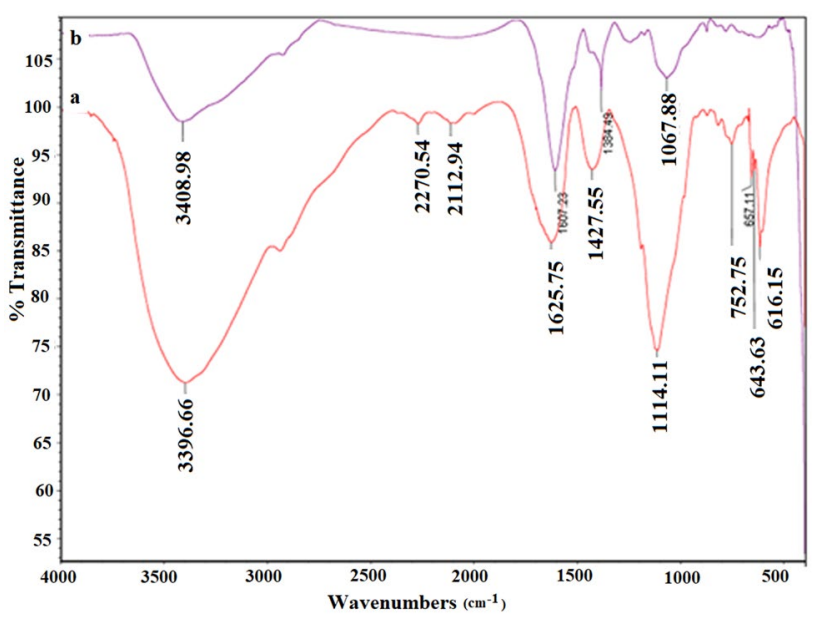

Fig. 4 a FTIR spectra of Tarragon extract, b Ag-MMT-NPs synthesized using the Tarragon extract

$(>\mathrm{C}=\mathrm{C})$, amines $(=\mathrm{N}-\mathrm{H})$, flavonoids, and amines $\left(-\mathrm{NH}_{2}\right)$, which are all in the range of $800-3442 / \mathrm{cm}$. The absorption band at $3396.66 / \mathrm{cm}$ in the spectrum might be attributed to the stretching vibrations of secondary amines of $\mathrm{N}-\mathrm{H}$ bond and bonded hydroxyl $(-\mathrm{OH})$ groups of phenols and carboxylic acids [18]. Bonded hydroxyl $(-\mathrm{OH})$ groups of carboxylic acids and phenols could produce absorption bands at $3396.66 / \mathrm{cm}$ (Fig. $4 \mathrm{a}$ ). In the AgNP spectrum, the new band at $1607.23 / \mathrm{cm}$ might suggest a new $\mathrm{C}=\mathrm{O}$ group (a ketone or an aldehyde) (Fig. 4b). FTIR spectroscopy was carried out to determine the potential biomolecules responsible for the reduction and capping of the AgNPs synthesized. The FTIR spectra of plant extract shows absorption bands characteristics of functional groups such as alcohol, phenol, amine, and carbonyl group.

In this manner, they essentially act as a capping agent, providing stability and preventing agglomeration for AgNPs. This phenomenon has been observed in the green synthesis of AgNPs using other plant extracts [37]. These findings confirm that phenolic agents and proteins in the Tarragon (Artemisia dracunculus) extract are responsible for the reduction of $\mathrm{AgNO}_{3}$ [22].

\section{TEM analysis}

As shown in (Fig. 5a), the TEM image shows the average size was about $25.12 \mathrm{~nm}$ with interring particle distance (Fig. 5b). The AgNPs are quasi-spherical in shape and no aggregation of AgNPs was observed. 

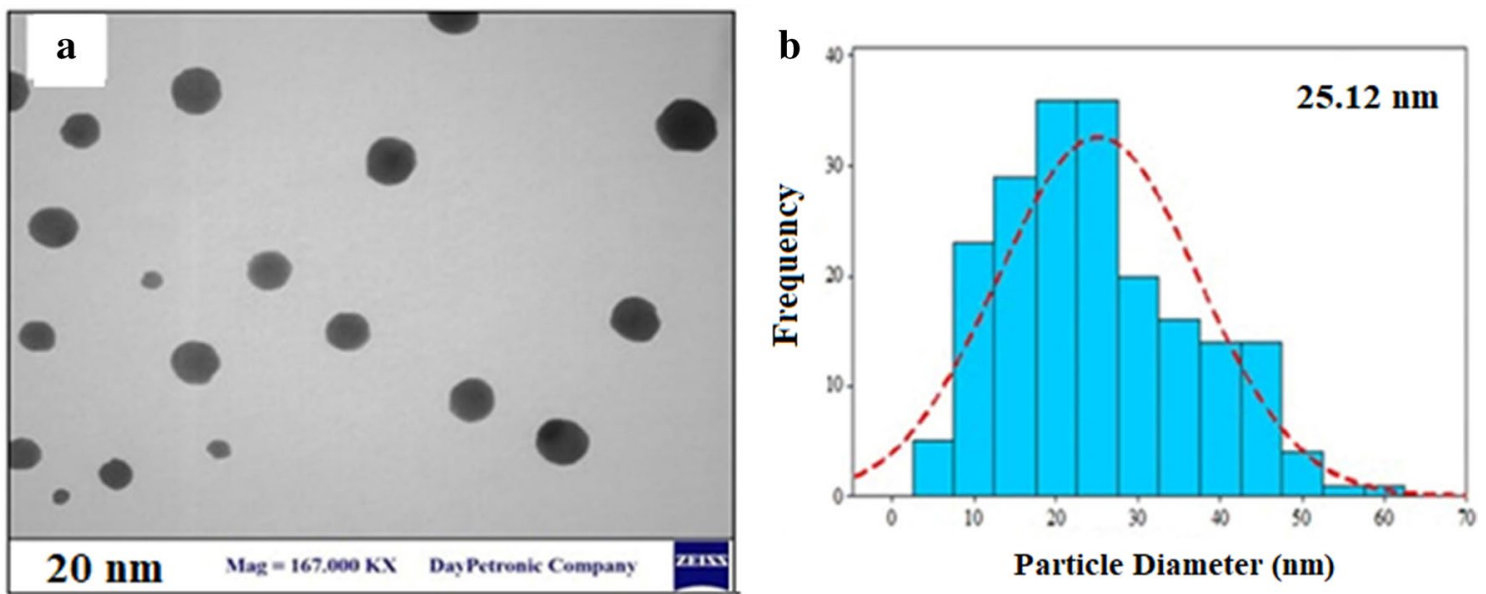

Fig. 5 a TEM image of the synthesized Ag-MMT-NPs with Tarragon extract; b particle size distribution of biosynthesized Ag-MMT-NPs

Fig. 6 Antibacterial activity of Ag-MMT-NPs against both a Gram-negative (E. coli) and b Gram-positive (S. aureus) in different solutions
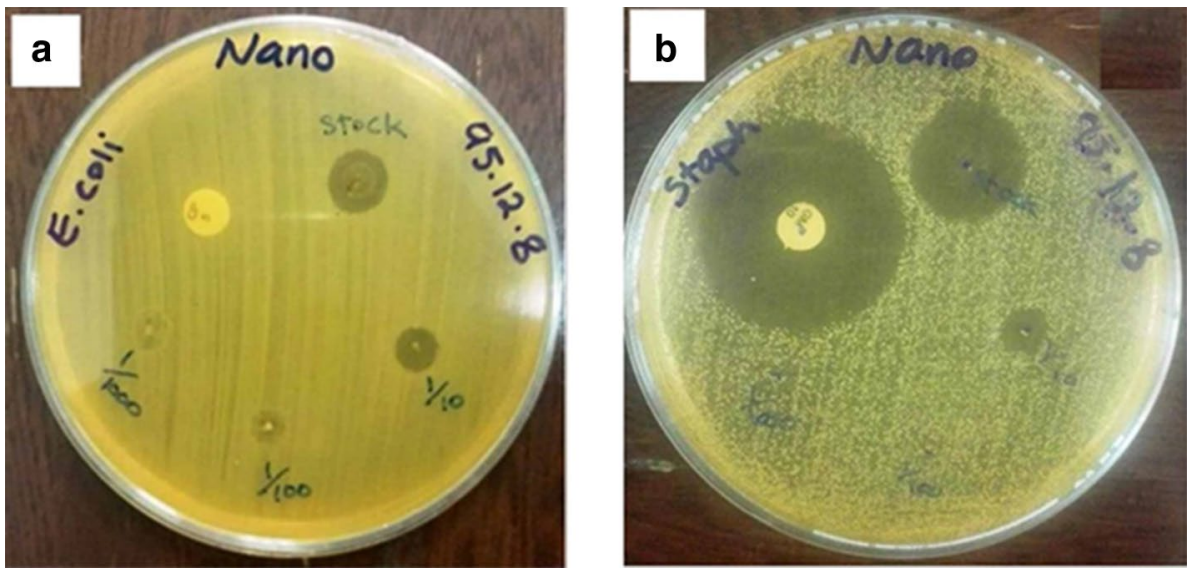

\section{Antibacterial activity}

For evaluating the antibacterial activity of AgNPs, both Gram-positive (S. aureus) and Gram-negative (E. coli) bacteria were used (Fig. 6). The inhibition zone of Ag-MMTNPs is listed in Table 1.

\section{Conclusion}

In the present research, a novel process was used for the synthesis of Ag-MMT-NPs with Tarragon extract as a reducing, nontoxic reagent and capping agent. Additionally, this method is easily adopted for the mass production of nanoparticles without requiring any extra compounds or physical processes and have well-defined size and morphology. The green synthesis of Ag-MMT-NPs with the extract is a more cost-effective and eco-friendly strategy, compared to physical and chemical synthesis methods. Optimization of $\mathrm{AgNO}_{3}$ and Tarragon extract concentration was achieved to obtain large amount of AgNPs in batch process. UV-Vis, FTIR, TEM, and XRD studies were performed to confirm the Ag-MMT-NPs formation. For AgNPs, UV-Vis peak was observed at $437 \mathrm{~nm}$. The crystalline structure of synthesized Ag-MMT-NPs was revealed on XRD. The Ag-MMTNPs had an anisotropic nature and a quasi-spherical shape (average size around, $25.12 \mathrm{~nm}$ ). 


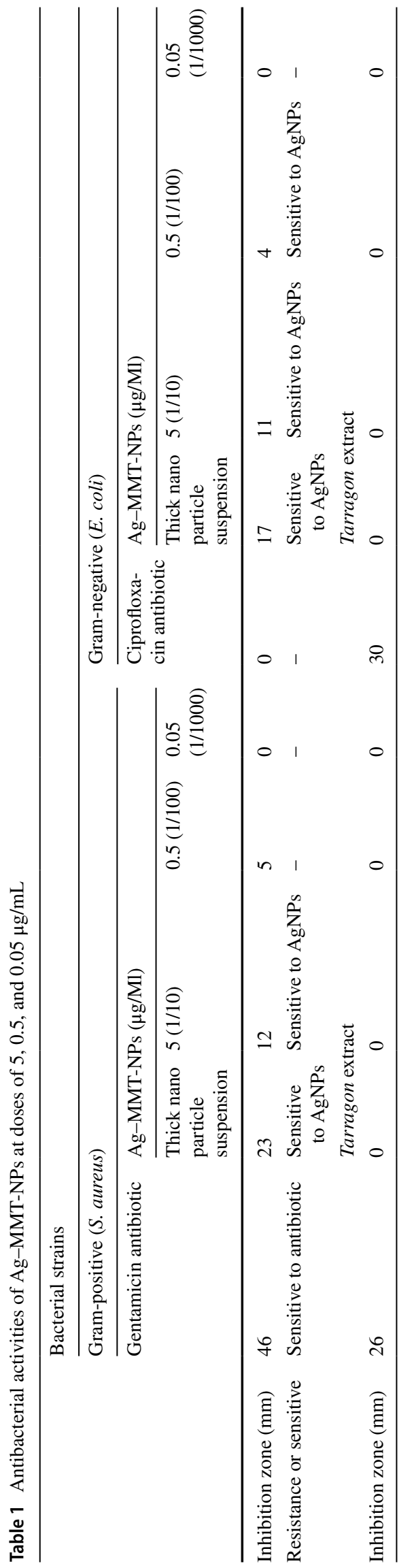

Acknowledgements This work was supported by North Tehran branch and Shahr-e-Qods Branch of Islamic Azad University of Iran. We thank these two Universities for their kind Cooperation.

Conflict of interests The authors declare that they have no conflict of interests.

Open Access This article is distributed under the terms of the Creative Commons Attribution 4.0 International License (http://creativeco mmons.org/licenses/by/4.0/), which permits unrestricted use, distribution, and reproduction in any medium, provided you give appropriate credit to the original author(s) and the source, provide a link to the Creative Commons license, and indicate if changes were made.

\section{References}

1. Ahmad, M., Ahmed, Sh, Ikram, S., Swami, B.L.: A review on plants extract mediated synthesis of silver nanoparticles for antimicrobial applications: a green expertise. J. Adv. Res. 7, 17-28 (2016)

2. Amooaghaie, R., Azizi, M., Saeri, M.R.: Synthesis, characterization and biocompatibility of silver nanoparticles synthesized from Nigella sativa leaf extract in comparison with chemical silver nanoparticles. Ecotoxicol. Environ. Saf. 120, 400-408 (2015)

3. Johnson, I., Prabu, J.: Plant-mediated biosynthesis and characterization of silver nanoparticles by leaf extracts of Tragia involucrata, Cymbopogon citronella, Solanum verbascifolium and Tylophora ovata. Int. J. Mod. Sci. 1, 237-246 (2015)

4. Tripathi, R.M., Gupta, R.K., Singh, P., Bhadwal, A.S., Shrivastav, A.: Ultra-sensitive detection of mercury (II) ions in water sample using gold nanoparticles synthesized by Trichoderma harzianum and their mechanistic approach. Sensor Actuat B. 204, 637-646 (2014)

5. Bhadwal, A.S., Tripathi, R.M., Gupta, R.K., Singh, R.P.: Biogenic synthesis and photocatalytic activity of CdS nanoparticles. RSC Adv. 4, 9484-9490 (2014)

6. Le, A.T., Nguyen, V.Q., Tran, Q.H.: Silver nanoparticles: synthesis, properties, toxicology, applications and perspectives. Adv. Nat. Sci. 4, 033001 (2013). https://doi.org/10.1088/20436262/4/3/033001

7. Mohammadzadeh, R.: Hypothesis: silver nanoparticles as an Adjuvant for cancertherapy. Adv. Pharm. Bull. 2, 133 (2012)

8. Abd-Elaal, A.A., Negm, N.A., Tawfik, S.M.: Synthesis, characterization and biological activity of colloidal silver nanoparticles stabilized by gemini anionic surfactants. J. Ind. Eng. Chem. 21, 1051-1057 (2015)

9. Akhtar, M.S., Mohanty, S.K., Sinniah, U.R., Swamy, M.K.: Synthesis and characterization of silver nanoparticles using fruit extract of Momordica cymbalaria and assessment of their in vitro antimicrobial, antioxidant and cytotoxicity activities. Spectrochim. Acta A. 151, 939-944 (2015)

10. Baharara, J., Hosseini, N., Namvar, F., Ramezani, T., Rosfarizan, M.: Green synthesis of silver nanoparticles using Achillea biebersteinii flower extract and its anti-angiogenic properties in the rat aortic ring model. Molecules 19(4), 4624-4634 (2014)

11. Bilal, M., Rasheed, T., Iqbal, H.M.N., Li, C., Hu, H., Zhang, X.: Development of silver nanoparticles loaded chitosan-alginate constructs with biomedical potentialities. Int. J. Biol. Macromol. 105, 394-400 (2017). https://doi.org/10.1016/j.ijbio mac.2017.07.047 
12. Nagajyothi, P.C., An, M., Lee, K.D., Lee, S.E.: Green synthesis of silver and gold nanoparticles using Lonicera Japonica flower extract. Bull. Korean Chem. Soc. 33(8), 2609 (2012)

13. Jagtap, U.B., Bapat, V.A.: Green synthesis of silver nanoparticles using Artocarpus heterophyllus Lam. seed extract and its antibacterial activity. Ind. Crop. Prod. 46, 132-137 (2013)

14. Iravani, S., Korbekandi, H., Mirmohammadi, S.V., Zolfaghari, B.: Synthesis of silver nanoparticles: chemical, physical and biological methods. Res. Pharm. Sci. 9, 385-406 (2014)

15. Salkar, R.A., Jeevanandam, P., Aruna, S.T., Koltypin, Y., Gedanken, A.: The sonochemical preparation of amorphous silver nanoparticles. J. Mater. Chem. 9, 1333-1335 (1999)

16. Prasad, T., Elumalai, E.: Biofabrication of $\mathrm{Ag}$ nanoparticles using Moringa oleifera leaf extract and their antimicrobial activity. Asian Pac. J. Trop. Biomed. 1(6), 439-442 (2011)

17. Baghizadeh, A., Ranjbar, Sh, Kumar Gupta, V., Asif, M., Pourseyedi, Sh, Mohammadinejad, R.: Green synthesis of silver nanoparticles using seed extract of Calendula officinalis in liquid phase. J. Mol. Liq. 207, 159-163 (2015)

18. Azizi, M., Sedaghat, S., Tahvildari, K., Derakhshi, P., Ghaemi, A.: Synthesis of silver nanoparticles using Peganum harmala extract as a green route. Green Chem. Lett. 10(4), 420-427 (2017)

19. Gottimukkala, K.S.V., Harika, R.P., Zamare, D.: Green synthesis of iron nanoparticles using green tea leaves extract. J Nanomed. Biother. Discov. 7, 151 (2017). https://doi.org/10.4172/2155983x.1000151

20. Sadeghi, B., Rostami, A., Momeni, S.S.: Facile green synthesis of silver nanoparticles using seed aqueous extract of Pistacia atlantica and its antibacterial activity. Spectrochim. Acta A. 134, 326-332 (2015)

21. Wang, Y., He, X., Wang, K., Zhang, X., Tan, W.: Barbated Skullcup herb extract-mediated biosynthesis of gold nanoparticles and its primary application in electrochemistry. Colloids Surf. B. Biointerfaces 73, 75-79 (2009)

22. Chandran, S.P., Chaudhary, M., Pasricha, R., Ahmad, A., Sastry, M.: Synthesis of gold nanotriangles and silver nanoparticles using Aloe vera plant extract. Biotechnol. Prog. 22, 577-583 (2006)

23. Khan, M.Z.H., Tareq, F.K., Hossen, M.A., Roki, M.N.A.M.: Green synthesis and characterization of silver nanoparticles using Coriandrum sativum leaf extract. JESTEC 13(1), 158-166 (2018)

24. Lin, L.-Z., Harnly, J.M.: LC-PDA-ESI/MS identification of the phenolic components of three compositae spices: chamomile, tarragon, and mexican arnica. Nat. Prod. Commun. 7(6), 749-752 (2012)

25. Aglarova, A.M., Zilfikarov, I.N., Severtseva, O.V.: Biological characteristics and useful properties of tarragon (Artemisia dracunculus). Pharm. Chem. J. 42, 81-86 (2008)

26. Obolskiy, D., Pischel, I., Feistel, B., Glotov, N., Heinrich, M.: Artemisia dracunculus L. (Tarragon): a critical review of its traditional use, chemical composition, pharmacology, and safety. J. Agric. Food Chem. 59(21), 11367-11384 (2011)
27. Raeisi, M., Tajik, H., Razavi, R.S., Maham, M., Moradi, M., Hajimohammadi, B., Naghili, H., Hashemi, M., Mehdizadeh, T. Essential oil of tarragon (Artemisia dracunculus) antibacterial activity on Staphylococcus aureus and Escherichia coli in culture media and Iranian white cheese. Iran. J. Microbiol. 4(1), 30-34 (2012)

28. Bagheriyan, S., Esmaeili, A., Sedaghat, S.: Biosynthesis of silver nanoparticles using Pennyroyal water extract as a green route. JNSC 6, 25-27 (2016)

29. Sithara, R., Selvakumar, P., Arun, C., Anandan, S., Sivashanmugam, P.: Economical synthesis of silver nanoparticles using leaf extracts of Acalypha hispida and its application in the detection of Mn ions. J. Adv. Res. 8, 561-568 (2017)

30. Allafchian, A.R., Mirahmadi-Zare, S.Z., Jalali, S.A.H., Hashemi, S.S., Vahabi, M.R.: Green synthesis of silver nanoparticles using phlomis. JNSC 6, 129-135 (2016)

31. Huang, J., Zhan, G., Zheng, B., Sun, D., Fenfen, L., Yuan, L., Chen, H., Zheng, Zh, Zheng, Y., Qingbiao, L.: Biogenic silver nanoparticles by Cacumen platycladi extract: synthesis, formation mechanism, and antibacterial activity. Ind. Eng. Chem. Res. 50, 9095-9106 (2011)

32. Shrivastava, S., Bera, T., Ro, A., Singh, G., Ramachandrarao, P., Dash, D.: Characterization of enhanced antibacterial effects of novel silver nanoparticles. Nanotechnology 18, 225103 (2007)

33. Ahmad, M., Azizi, S., Mahdavi, M., Mohamad, R., Namvar, F.: Biosynthesis of silver nanoparticles using brown marine macroalga, Sargassum muticum aqueous extract. Materials 6, 5942$5950(2013)$

34. Muniyappan, N., Nagarajan, N.S.: Green synthesis of silver nanoparticles with Dalbergia spinosa leaves and their applications in biological and catalytic activities. Process Biochem. 49, 10541061 (2014)

35. da Silvia Cordeiro, T.H., de Matos, R.A., Samad, R.E., Vieira, N.D.: Green synthesis of stable silver nanoparticles using Euphorbia milii latex. Colloid Surf. A 389, 134-137 (2011)

36. Dipankar, C., Murugan, S.: The green synthesis, characterization and evaluation of the biological activities of silver nanoparticles synthesized from Iresine herbstii leaf aqueous extracts. Colloid. Surf. B 98, 112-119 (2012)

37. Vidhu, V.K., Aromal, S.A., Philip, D.: Green synthesis of silver nanoparticles using Macrotyloma uniflorum. Spectrochim. Acta A 83(1), 392-397 (2011)

Publisher's Note Springer Nature remains neutral with regard to jurisdictional claims in published maps and institutional affiliations. 